\title{
Exploration of Effective Instructional Design in PAD Classroom
}

\author{
Jing Ma \\ School of Computer Science and Engineering \\ Xi'an Technological University, \\ Shaanxi Xi'an 710021, China \\ e-mail: 410329074@qq.com
}

\begin{abstract}
In the classroom teaching method, the simple teaching leads to the interaction between teachers and students with little interaction, students are often passive acceptance, lack of substantive participation, initiative is not strong, it is difficult to cultivate thinking ability and exploration spirit. Professor Zhang Xuexin of Fudan University has put forward the PAD teaching mode, which has led to new thinking about classroom teaching in China. The PAD class can promote the teachers to reform teaching contents and teaching methods, can help students learn to learn, reflection, practice and innovation. This paper, based on PAD class mode, combined with the design of task order, enables PAD class to achieve more efficient classroom tasks.
\end{abstract}

\section{Keywords : PAD; Flipped Classroom; Teaching Design}

\section{INTRODUCTION}

Higher education has the function of scientific research, serving the society and training professional talents. At present, China has made remarkable achievements in the reform of higher education, but there are still some problems in the development. Since the massive expansion of education in 1999, China's education has been transformed from elite education to education with unprecedented speed. In 2014, the total number of students of all kinds of higher education students in the country reached 3.559 million, and the gross enrollment rate of education was $37.5 \%$.

During the "12th Five-Year" period, China's higher education has entered a new normal development centered on quality improvement. In recent years, both the first-line teachers or teaching management level, are trying to teaching the model of innovation, teaching methods of reform, as well as learning the way of innovation, and strive to improve the level of personnel training.

In order to change the students' passive classroom learning habit, the author attempts to put forward the PAD classroom proposed by Professor Zhang Xuexin of Fudan University in china. PAD class tries to stimulate students' learning enthusiasm and autonomy, to establish the students' main role in learning and to take active learning.

Wang Xia, a teacher at Fuyang Normal College, applies the PAD model in English teaching, which improves the students' autonomy and reading quality in reading teaching. Fudan University teacher Liu Mingqiu's practice shows that microbiology PAD classroom can enhance students' sense of achievement, and get good learning results. Shanghai Jiao Tong University Su Liuliu teacher's ideological and political education, Wenshan College Song Jianping, Wang Hongbin teacher's organic chemistry PAD classroom have received good results. According to incomplete statistics, since 2013, PAD class has 69 schools, 178 class in practice, the range of higher education, vocational education and the education of primary and secondary schools, the results show that by designing effective classroom teachers, PAD to improve classroom teaching quality and teaching effect.

\section{PAD CLASS MODE}

PAD advocated distributing the half of the class time to classroom teachers to teach knowledge, half the class time allocated to the student, the form of interactive learning through group discussion, to achieve the understanding of knowledge. PAD class divides teaching into time: presentation, assimilation and discussion. The basic flow of PAD class is shown in figure 1 . Notice that we're going to be talking about the last lecture.

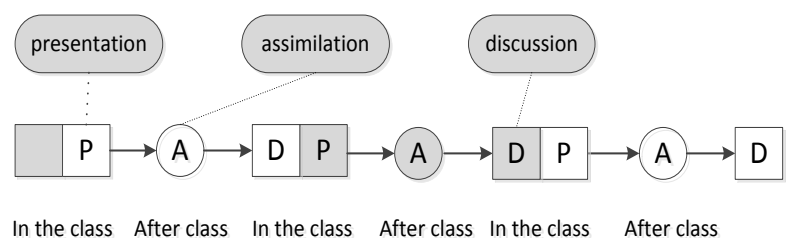

Figure 1. Basic procedures of PAD class

PAD classroom is similar to the traditional classroom, emphasizing the teaching of teachers first, students learn later. At the same time, it is similar to the discussion class, emphasizing teacher-student interaction and student-student interaction, encourage students to study independently. The highlight of PAD class is mainly to separate classroom teaching from classroom discussion, so that students can have a certain time for personalized study after class and internalize the knowledge taught by teachers. In addition, in the evaluation way, so that each student can be based on their learning objectives to determine the input of the course.

\section{A. Presentation}

The lecture content in PAD class is different from that in traditional class. The teaching content of PAD class is based on the knowledge summary, and tells the students the main knowledge points to be learned in the next class, including the important background, concepts and viewpoints, etc. The goal is to help students build a knowledge framework, grasp the focus, and let students know what they want to 
learn. And then publish the next course of study tasks, tell students should achieve the goal and need to think about the problem.

Classroom instruction should tell students what to learn, why to learn and how to learn. What to learn is to tell students the key points and difficulties in learning, and arrange the learning framework. Why to learn is to point out the meaning and value of learning content, such as laying the foundation for other content or the needs of real life, etc. How to learn is to provide learning methods, skills and strategies so that students can complete the study after class more effectively. It can be a learning method for specific chapters, or a more general general learning method. The purpose is to let students gradually learn to reflect and optimize their learning process.

PAD classroom teaching is like the roadmap in the learning process, let students understand the content of the situation, understand the learning content of their own use, know their own to achieve specific learning goals, students will feel very different from the past, learning interest will be excited.

\section{B. Assimilation}

After class teaching, students will be taught themselves after class. According to the instructions on the task list, students will be taught to study and prepare for the discussion in the next class.

After class study mainly includes reading, review, independent thinking, complete the homework. In order to help students learn more effectively and prepare content for the next lesson, the task list of homework should be able to guide students to review after class, help them to understand the basic content, ready for further group discussion and exchange.

A person's mistakes are more likely to be discovered by others than by themselves. The principle of homework assignment is to make students have doubts in the process of independent learning, so that they can solve their own doubts in the next class discussion. Teachers should remind students to plan their own time and determine how much they invest in their homework according to their own time.

\section{Discussion}

The teacher can review the content and task requirements of the last class in 1 2 minutes, and then start the discussion. The contents of the discussion are the assignments on the task list. The team members report their own gains, ask other members of their own questions, and tell their own questions to help the team members solve the problem. In order to ensure the efficiency and quality of the discussion, the discussion is divided into four sections: group discussion, teacher sampling, free questioning and summary of teachers.

The discussion should give everyone an opportunity to express themselves and learn from each other in terms of their own gains, confusions and difficulties. The form of group discussion can be varied. For example, you can insert cross group discussions, such as making each group number
1 form a new group, in order to expand the scope of student communication.

PAD class teaching goal is to allow students to find their own problems, and clearly expressed, first through group discussion try to solve, if not solve, can be solved by the teacher.

\section{EFFECTIVE COURSE TEACHING DESIGN THROUGH TASK LIST}

The task list is to provide students with a support to study independently and to help students determine if they have completed their learning goals. Teachers should inform students teaching goal, through the pre class tasks, to develop measurable teaching objectives, such as through the pre class test to assess the basic knowledge points in the course, to help students measure learning outcomes.

\section{A. Pre-class study guide}

Learning guidelines include learning outcomes, achieving goals, learning method recommendations and classroom learning styles. Through the design of learning guide, students can make clear the theme of autonomous learning and meet the requirements of the target, know what kind of way to achieve learning goals. In teaching design, we should first consider the teaching content. We analyzed the whole course and sorted out the main contents of the course. According to the time arrangement of the course, set the specific goal of each lesson. Teaching goals can help students understand what they should know and how they learn that knowledge.

For example, in this section of the assembly language, we will learn arithmetic operation instructions, logical operation instructions, and shift instructions. The Pre-class learning guide is shown in table 1.

\section{B. Three basic tasks}

How to guide students to think about problems? The thinking question should revolve around the curriculum, but also let the student be able to discover own insufficiency, more importantly should be able to help the student carry on the effective discussion in the classroom, to make up for the blank in the study.

There are three basic tasks listed on the task list:

1) Take out what I've learned

Students will gain something in the process of learning. This task is to let students record what they learn in the process of learning.

\section{2) Examination of others did not learn}

This assignment refers to the fact that you have learned it in the learning process, but think that other people may be confused and expressed in the form of questions.

3) Ask someone to help me solve what I do not understand

This assignment is for students to write down what they don't understand or what they want to know in their learning process. To present the problem in the form of the problem, ask the other team members to solve the problem in the next class. 
TABLE.I. PRE-CLASS LEARNING GUIDE

\begin{tabular}{|l|}
\hline Pre-class learning guide \\
\hline 1 learning outcomes \\
(1) master the basic operation of arithmetic operation instruction \\
(2) master the basic operation of logical instructions \\
(3) master the basic operation of shift instruction \\
\hline 2 achieving goals \\
The preview target(the basic goal to be reached in the preview) \\
(1) can speak the operation of the arithmetic operation instruction \\
(3) can write the correct arithmetic instructions \\
(4) can write the correct logic instructions \\
(5) can say the operation of the shift instruction \\
(6) can write the correct shift instruction \\
classroom goals (in the classroom to further deepen the advanced goals) \\
(1) can use the arithmetic instruction to complete the simple four mixed \\
operation programming \\
(2) can summarize the application of logical instructions, and select the \\
appropriate instruction to complete the task \\
(3) can apply the shift instruction to complete programming \\
\hline 3 learning method recommendations \\
Watch the micro-class video, read the study materials, do pre-class test \\
\hline 4 classroom learning styles \\
The group discussed the assignments on the task list \\
\hline
\end{tabular}

The first task is to let students tell their members what they have learned before class. The second task is to allow students to list the question to ask someone else, by asking others to cause students to think further. The third task is to solve the final problem, there are always some problems that students can not solve themselves, before class discussion to find these problems, can make the discussion more efficient.

The homework emphasizes the use of knowledge. Whether it is "learning" or "asking", there is no shortage of positive thinking, learning and thinking together, the knowledge into their own experience. Teaching is "teaching" and "learning" process, but also the process of communication, job feedback is a communication, teachers and students can communicate through the text of ideas, closer to each other's distance, build a good teacher-student relationship.

\section{Learning activities}

After learning and preparation, all the students are also very clear about the issues to be discussed in class, which can greatly improve the discussion effect. Different division of group discussion, let students not only gain knowledge in the discussion, more important is to learn to communicate with others, learn how to solve problems with the help of others, and within their own ability to help others.

Learning activities design such as table 2.

TABLE.II. LEARNING ACTIVITIE

Learning activitie
Group discussion:
Group members: each group of five
Time arrangement: 20 minutes
Role arrangement:
Team leader, timer, record keeper, representative (each group
determines the division of labor, but each time should be different,
when the group discussion, the recorder should record the contribution
of each team member)
Content of discussion:
Conclusion:
Contribution:

\section{CONCLUSION}

PAD classroom is a kind of teaching method which accords with the basic psychological rules of learning process. Teachers can become the guide of students' learning through the design of learning task list. In the teaching process, the teacher is the knowledge of the transfer, the student is the knowledge recipient. In the process of internalization and absorption, teachers are the evaluators of students' learning achievements, and students are the discoverer of knowledge. In the discussion, the teacher is the organization guider, and the student is the knowledge communicator. In the whole process, the main body status of students gradually increased, significantly improved the enthusiasm of independent learning, active classroom atmosphere, enhanced students' learning initiative and initiative.

\section{ACKNOWLEDGMENTS}

The work described in this paper was fully supported by Key educational reform fund of Xi'an Technological University(NO. 15JGZ05), Project Name is Research on new teaching system of micro course based on students' learning needs.

\section{REFERENCES}

[1] Xuexin zhang, The PAD Class :New Wisdom of Chinese Education, Science press, (2016)

[2] Tie-fang liu. Discussion on communication in education and its barrier [J]. China education journal, 1996(3) : 16-20

[3] Yong-an li. Reform strategy of Chinese university classroom teaching [J]. China higher education, 2013 (5) : 33-35

[4] Li xiaonang, wang yunwu. Research on microcurriculum design and teaching application in micro learning vision [J]. Modern education technology, 2013(10):31-35.

[5] Alberto, P.,and A. Troutman. 2009.Applied behavior analysis for teachers. 8th ed. Upper Saddle River, NJ :Pearson. 